\title{
Should We Perform Early Cataract Surgery? A Patient Reported Outcome Study
}

\section{Eilidh Farquhar* \\ Umiya Harley* \\ Alan Rotchford \\ Kanna Ramaesh}

Tennent Institute of Ophthalmology, Gartnavel General Hospital, Glasgow, UK

*These authors contributed equally to this work
Correspondence: Umiya Harley

Tennent Institute of Ophthalmology,

Gartnavel General Hospital, 1053 Great

Western Road, Glasgow, GI2 OYN,

United Kingdom

Email umiya.harley@nhs.net
Purpose: Current guidance states that access to cataract surgery should not be restricted by visual acuity (VA); nevertheless, 6/12 is used as a cut-off criterion in some health institutions. This study aims to determine the benefits of performing cataract surgery in patients with VA of $6 / 9$ or better in both eyes; determine whether these benefits change over time; and compare the benefit observed between early first eye and second eye surgery.

Patients and Methods: Fifty adults with VA at least $6 / 9$ in the worst eye and no ocular comorbidity were recruited. The Visual Function Index (VF-14) and Impact of Visual Impairment (IVI) questionnaires were conducted pre-operatively, 4 months postoperatively, and 12 months post-operatively. The $t$-test or a non-parametric equivalent was used to compare averages between groups.

Results: The mean change in VF-14 from baseline to 4 months was 16.43 (95\% CI 12.49-20.50, $\mathrm{p}<0.001$ ) and the median change in IVI was 6.5 (IQR 9.75, $\mathrm{p}<0.001$ ). There was no significant difference between 4-month and 12-month follow-up $(\mathrm{p}>0.05)$. There was no significant difference in the change in visual function between the first and second eye surgery $(p>0.05)$.

Conclusion: This study provides evidence that visual function improves after cataract surgery in patients with pre-operative VA of 6/9 or better. The improvement observed was clinically significant and unchanged a year after surgery. Visual function improved after second eye as much as after first eye surgery. Assessing patient reported visual function may give a more realistic indication of the benefit of early cataract surgery than relying on VA alone.

Keywords: visual function, cataract surgery, patient reported outcomes

\section{Introduction}

Cataract surgery has been shown to improve visual function to an extent, which is poorly correlated with pre-operative best-corrected visual acuity (BCVA). ${ }^{1-4}$ The majority of work assessing patient-reported visual function outcomes has included a wide range of pre-operative BCVA. ${ }^{1,2,4-6}$ Using such evidence, guidance produced by the National Institute for Health and Clinical Excellence (NICE) states that surgery should not be withheld on the basis of BCVA. ${ }^{7}$ However, it is not yet clear whether early surgery is clinically justified, since comparisons of the mean visual function before and after surgery within broad cohorts may mask effects within the group of patients with early only cataract.

Despite NICE guidance, some health institutions and service providers in areas of the United Kingdom (UK) have discouraged referral of patients with BCVA better than $6 / 12$ as pressures to deliver services have increased. ${ }^{8-10}$ Previous work in this field has included patients whose BCVA had already dropped below 6/12, 
did not assess the BCVA, or retrospectively reviewed visual function changes at variable and often short lengths of follow-up. ${ }^{3,11-13}$ Robust evidence to support early cataract surgery and rebut attempts to restrict access based on an arbitrary BCVA cut-off is therefore lacking.

Further research is required to ascertain the quantitative visual function benefit of cataract surgery when the BCVA is better than $6 / 12$ in order to justify services providing access to early surgery. In this study, we aimed to investigate whether a clinically significant improvement in visual function was observed after cataract surgery in symptomatic cataract patients with a pre-operative BCVA of 6/9 or better in their worst eye. Two validated and widely used patient reported outcome questionnaires were used to measure visual function changes at both 4 months and 12 months post-operatively to assess the stability of the findings. This study included both first and second eye patients as the latter are even more prone to exclusion from surgery by service providers, and the benefit of second eye surgery is unclear with previous conflicting results. $^{13,14}$

A secondary aim of this study was to investigate whether particular patient-related factors and specific domains of the questionnaires were associated with greater improvement in overall visual function, to aid patient selection when assessing for cataract surgery.

\section{Materials and Methods}

This observational cohort study adhered to the tenets of the Declaration of Helsinki. Ethical approval was granted by the Black Country Research Ethics Committee, and informed consent was obtained from all participants.

Fifty patients listed for first or second eye phacoemulsification and monofocal intraocular lens implant with BCVA of $6 / 9$ or better in both eyes were recruited. Patients with any visually significant ocular comorbidity in either eye, multifocal implants, or those who were under 18 years of age were excluded. Recruitment ran from December 2016 to December 2018 from pre-operative assessment clinics at Gartnavel General Hospital, Stobhill Ambulatory Care Hospital, the New Victoria Hospital, and the Golden Jubilee National Hospital, all of which are in Glasgow.

For the 28 patients recruited at pre-operative assessment, BCVA was measured uniocularly using a Snellen chart at 6 meters before pupil dilation. The 22 patients recruited on the day of surgery were already dilated so the un-dilated BCVA recorded at pre-operative assessment was used instead. The type and severity of cataract was graded according to the Lens Opacity Classification System (LOCS (iii)). ${ }^{15}$
Visual function was measured with two validated patientreported outcome tools: the Visual Function Index (VF-14) and Impact of Visual Impairment (IVI) questionnaires. Both questionnaires were repeated via telephone at 4 months then 12 months post-operatively. Post-operative BCVA was taken from routine 4-week follow-up.

In the VF-14, patients rate how much difficulty they have with activities such as reading, seeing stairs, and driving, from "none", "a little", "moderate", "a great deal", "unable to do", or "not applicable". An overall score between 0 and 100 is calculated, with higher scores signifying better visual function. ${ }^{16}$

For the IVI, patients are asked to consider the past month and rate how much their vision has interfered with activities including travelling and reading medicine labels as well as emotional well-being, from "not at all", "a little", "a fair amount" or "all the time". The total score has a maximum of 84 and a minimum of 0 , with lower scores signifying better visual function. ${ }^{17}$

Statistical analysis was carried out using IBM SPSS version 24.0. BCVA was converted to LogMAR for analysis. Patients with missing data were not included in the comparative statistical analyses. The data were first tested for normality with the Shapiro-Wilks test. To assess the change in visual function from baseline to 4 months and from 4 months to 12 months, the paired $t$-test was used as a parametric test of the means for normally distributed data and the Wilcoxon signed-rank test was used as a non-parametric test of the medians for non-normally distributed data.

To investigate correlations between the change in visual function and age, LOCS (iii) grade, response to specific questions, and change in BCVA, the parametric Pearson correlation coefficient $r$ was used for normally distributed data and the non-parametric Spearman correlation coefficient $\rho$ for non-normally distributed data. The data were then split into groups based on pre-operative BCVA, type of cataract, and first or second eye. The independent samples $t$-test was used to compare the mean difference between groups where normally distributed and the Mann-Whitney $U$-test was used to compare groups with non-normally distributed data.

All tests were 2-tailed. An alpha level of 0.05 was used to determine the statistical significance. Clinical significance was defined as a change of 4 or more on the IVI, based on the only reported minimal clinically important difference for the raw score of the IVI, ${ }^{18}$ and a change of 5.5 or more on the VF-14, based on the most relevant literature for this study sample. ${ }^{19}$ Using a predicted standard deviation of 13 , the 
required sample size was calculated to be 46 patients for $80 \%$ power to detect a difference of at least 5.5 for the VF-14.

\section{Results}

Of 50 patients recruited, 48 (96\%) completed 4-month follow-up and 43 (86\%) completed 12-month follow-up. Demographics and background details are shown in Table 1. There was a statistically significant improvement in VF-14 (74.53 to 90.96) and IVI (16.44 to 5.81) from baseline to 4 months, as shown in Table $2(\mathrm{p}<0.001)$. Forty-

Table I Demographic Data at Baseline

\begin{tabular}{|l|c|}
\hline $\begin{array}{l}\text { Age } \\
\text { Mean } \pm \text { SD }\end{array}$ & $\begin{array}{c}\text { Range } 36-89 \\
69.8 \pm 11.3\end{array}$ \\
\hline Gender & 28 female (58\%) \\
& 20 male (42\%) \\
\hline Operated eye & 22 Ist eye (46\%) \\
& 262 nd eye (54\%) \\
\hline LOCS(iii) grade & NO $2.50 \pm 1.07$ \\
Mean \pm SD & NC $2.86 \pm 0.91$ \\
& P $0.61 \pm 1.06$ \\
& C I.27 \pm 1.24 \\
\hline
\end{tabular}

Abbreviations: SD, standard deviation; LOCS(iii); Lens Opacity Classification System; NO, nuclear opalescence; NC, nuclear color; P, posterior sub-capsular cataract; C, cortical cataract. four patients $(92 \%)$ showed a clinically significant improvement on one or both questionnaires; 5 patients had worse scores after surgery for one questionnaire but not the other; only 1 patient showed clinically significant worsening on both the VF-14 and the IVI. A visual representation of the change observed for each individual is shown in Figure 1. There was no significant difference between 4 months and 12 months for either the VF-14 or the IVI. Further statistical analysis was therefore completed using 4-month data only, to reduce the number of statistical tests undertaken.

Table 3 displays the results of the subgroup analyses. There was no significant difference in the change in visual function score from baseline to 4 months for patients undergoing first eye surgery compared to second eye surgery. There was no significant difference in outcome for patients with BCVA of $6 / 6$ or better compared to patients with BCVA of $6 / 7.5$ or $6 / 9$ in the operated eye. A greater improvement was observed in patients with posterior subcapsular cataract (PSCC) than with nuclear and/or cortical cataract, although this difference only reached statistical significance for the IVI.

No significant correlation was observed between the change in visual function and age or change in BCVA, but some significant correlations were found between the baseline response to selected questions and the overall

Table 2 Change in BCVA and Visual Function from Baseline to Follow-Up

\begin{tabular}{|c|c|c|c|c|c|c|}
\hline & \multirow{2}{*}{$\begin{array}{l}\text { Baseline } \\
\text { Results }\end{array}$} & \multicolumn{2}{|c|}{4 Months Post-Op $(n=48)$} & \multicolumn{3}{|c|}{12 Months Post-Op $(n=43)$} \\
\hline & & Results & $\begin{array}{l}\text { Difference From } \\
\text { Baseline Average (Cl) }\end{array}$ & Results & $\begin{array}{l}\text { Difference From } \\
\text { Baseline Average (Cl) }\end{array}$ & $\begin{array}{l}\text { Difference From } 4 \\
\text { Months Average (Cl) }\end{array}$ \\
\hline \multicolumn{7}{|c|}{ LogMAR BCVA } \\
\hline Mean & $0.13 \pm 0.12$ & $0.02 \pm 0.13$ & 0.12 (0.07 to 0.18$)$ & & & \\
\hline \multicolumn{7}{|c|}{ VF-14 score } \\
\hline Mean & $74.53 \pm 14.36$ & $90.96 \pm 11.30$ & 16.43 (12.49 to 20.50$)$ & $93.57 \pm 8.65$ & $19.70(15.31$ to 24.08$)$ & $3.23(-0.19$ to 6.64$)$ \\
\hline Median & & & 14.44 (10.44 to 20.64$)$ & & 18.27 (12.50 to 26.86$)$ & $0.00(-0.7$ to 3.52$)$ \\
\hline$p$ value & & & $<0.001^{\mathrm{a}}$ & & $<0.001^{a}$ & $0.154^{\mathrm{b}}$ \\
\hline \multicolumn{7}{|c|}{ IVI score } \\
\hline Mean & $16.44 \pm 12.38$ & $5.81 \pm 11.08$ & $-10.63(-14.31$ to -6.94$)$ & $3.28 \pm 5.73$ & $-14.07(-17.42$ to -10.72$)$ & $-2.12(-4.54$ to 0.31$)$ \\
\hline Median & & & $-9.00(-13.00$ to -6.00$)$ & & $-12.00(-17.00$ to -7.00$)$ & $0.00(-2.00$ to 0.00$)$ \\
\hline$p$ value & & & $<0.001^{\mathrm{b}}$ & & $<0.001^{\mathrm{b}}$ & $0.077^{\mathrm{b}}$ \\
\hline
\end{tabular}

Notes: ${ }^{a}$ Paired $t$-test, using mean difference, and ${ }^{b}$ Wilcoxon signed-rank test, using median difference, to compare visual acuity and questionnaire scores from baseline to 4 months, from baseline to 12 months, and from 4 months to 12 months. Visual acuity presented is for operated eye only. Post-operative visual acuity measurement taken from routine 4 week follow up. Means presented \pm standard deviation.

Abbreviations: BCVA, best corrected visual acuity in operated eye; VF-I4, Visual Function Index; IVI, Impact of Visual Impairment; Cl, 95\% confidence interval or closest approximation for medians. 

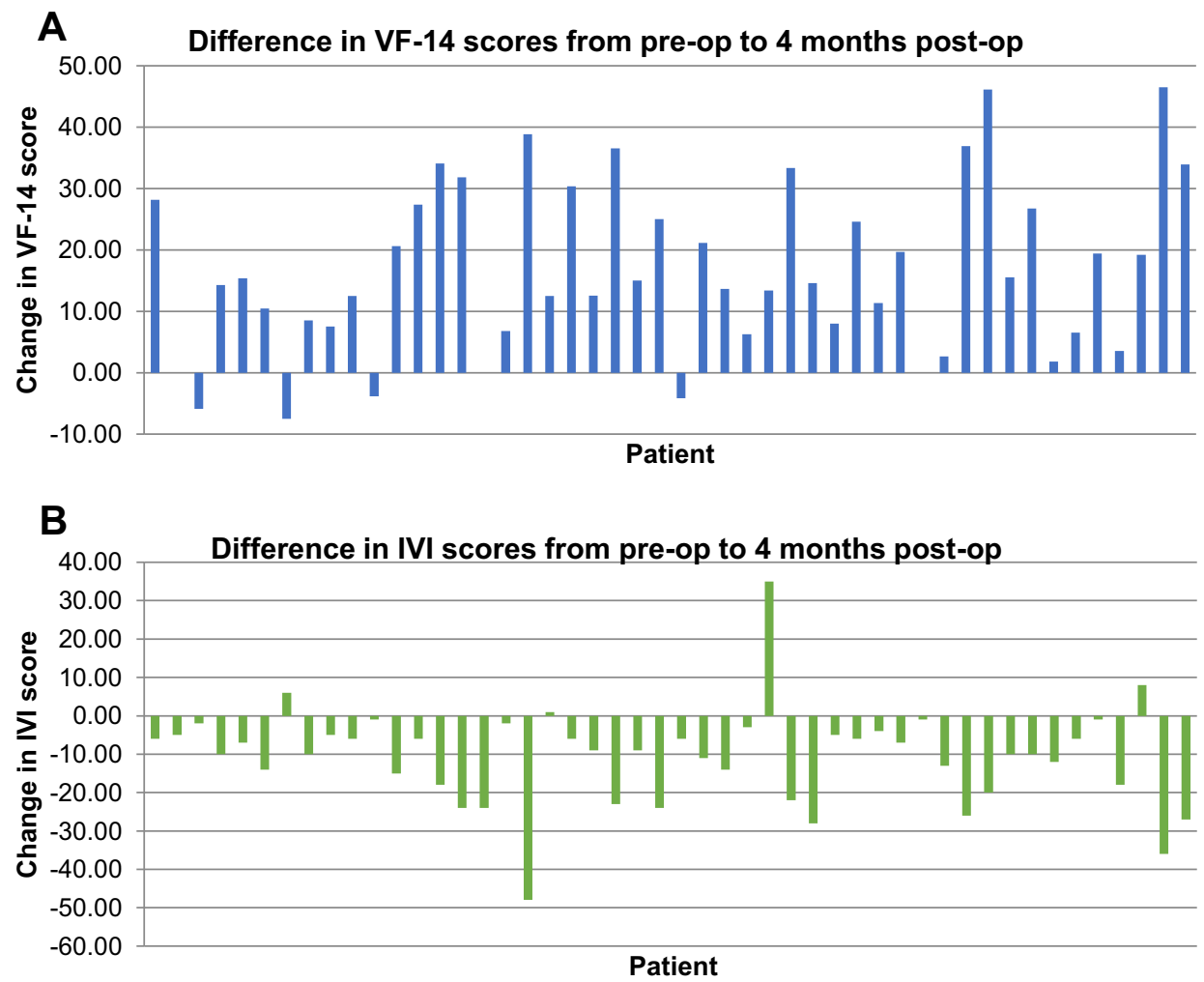

Figure I Bar graphs showing the change in visual function for each patient from baseline to 4 months. Each bar represents I patient. Patients displayed in the same order for both plots. (A) Visual Function Index, more positive = greater improvement; $(\mathbf{B})$ Impact of Visual Impairment questionnaire, more negative $=$ greater improvement.

change in visual function, as shown in Table 4. The questions to be analyzed were selected based on previous work, which identified reading small print and driving at night to be correlated with cataract surgery satisfaction ${ }^{20,21}$ and on visual inspection of the data.

\section{Discussion}

This study provides evidence that visual function improves after cataract surgery in patients with pre-operative BCVA of $6 / 9$ or better in both eyes. The mean visual function 4 months after surgery was substantially and statistically significantly better than pre-operatively and far in excess of the minimal clinically important difference. There was no loss of this improved visual function at 12 months compared to 4 months indicating the effect was stable.

These results are consistent with previous work, which has found a subjective improvement in visual function after cataract surgery, ${ }^{1-4}$ even in early cataract. ${ }^{11-13}$ However, this is the first prospective study to quantify that improvement in patients selected exclusively according to BCVA pre-operatively of $6 / 9$ or better in both eyes, which has been used in clinical practice as an arbitrary cutoff for accessing surgery. The finding that the benefit observed after early cataract surgery does not change significantly over time is also a novel contribution.

Over $90 \%$ of patients showed clinically significant improvement on one or both questionnaires. The cut-off of 4 for clinical significance on the IVI was taken from Finger et $a{ }^{18}{ }^{18}$ which is to our knowledge the only paper that has calculated a minimal clinically important difference for the raw score of the IVI. Finger et al considered the functional and emotional questions of the IVI separately; the larger cut-off was used here and applied to the overall score.

For the VF-14, varying cut-offs have been calculated. In a Spanish study, Bilbao et $\mathrm{al}^{22}$ found a minimal clinically important difference of 15 , but this reduced to 5 when the sample was restricted to patients scoring 70 or more preoperatively. ${ }^{23}$ Black et al ${ }^{19}$ found a minimal clinically important difference of 5.5 in the UK population. Since this study included only early cataract patients, pre-operative VF-14 scores were expected to be high. For this reason, and because we used a UK sample, the cut-off reported by Black et al ${ }^{19}$ was used.

Some authors have questioned the effectiveness of second eye surgery. ${ }^{24}$ Previous results have been mixed, with some reporting less benefit from second eye surgery 
Table 3 Comparison of Change in Visual Function by Operated Eye, Pre-Operative BCVA, and Type of Cataract

\begin{tabular}{|c|c|c|c|}
\hline Questionnaire/Group & $\begin{array}{l}\text { Mean Change } \\
( \pm \text { SD) }\end{array}$ & $\begin{array}{l}\text { Median } \\
\text { Change (IQR) }\end{array}$ & p-value \\
\hline \multicolumn{4}{|l|}{ VF-14 } \\
\hline $\begin{array}{l}\text { Ist eye }(n=22) \\
2 n d \text { eye }(n=26)\end{array}$ & $\begin{array}{l}14.83 \pm 12.53 \\
17.90 \pm 14.89\end{array}$ & & $0.448^{\mathrm{a}}$ \\
\hline \multicolumn{4}{|l|}{ IVI } \\
\hline $\begin{array}{l}\text { Ist eye } \\
\text { 2nd eye }\end{array}$ & & $\begin{array}{l}-10(13.5) \\
-6.5(12.5)\end{array}$ & $0.541^{\mathrm{b}}$ \\
\hline \multicolumn{4}{|l|}{ VF-14 } \\
\hline $\begin{array}{l}6 / 6 \text { or better }(n=15) \\
6 / 7.5 \text { or } 6 / 9(n=33)\end{array}$ & $\begin{array}{l}17.57 \pm 12.77 \\
16.01 \pm 14.41\end{array}$ & & $0.721^{\mathrm{a}}$ \\
\hline \multicolumn{4}{|l|}{ IVI } \\
\hline $\begin{array}{l}6 / 6 \text { or better } \\
6 / 7.5 \text { or } 6 / 9\end{array}$ & & $\begin{array}{l}-7(12) \\
-9(15.5)\end{array}$ & $0.824^{\mathrm{b}}$ \\
\hline \multicolumn{4}{|l|}{ VF-14 } \\
\hline $\begin{array}{l}\operatorname{PSCC}(n=14) \\
\text { No PSCC }(n=34)\end{array}$ & $\begin{array}{l}20.50 \pm 13.56 \\
14.85 \pm 13.76\end{array}$ & & $0.20 \mathrm{I}^{\mathrm{a}}$ \\
\hline \multicolumn{4}{|l|}{ IVI } \\
\hline $\begin{array}{l}\text { PSCC } \\
\text { No PSCC }\end{array}$ & & $\begin{array}{l}-16(17.25) \\
-6(9.5)\end{array}$ & $0.040^{\mathrm{b}}$ \\
\hline
\end{tabular}

Notes: andependent samples $t$-test and ${ }^{\mathrm{b}} \mathrm{Mann}-$ Whitney $U$-test comparing change in visual function from baseline to 4 months between Ist eye patients and 2 nd eye patients, between patients with pre-operative best corrected visual acuity of $6 / 6$ or better vs patients with pre-operative best corrected visual acuity of $6 / 7.5$ or $6 / 9$ in the operated eye, and between patients with posterior sub-capsular cataract vs patients with cortical and/or nuclear cataract only.

Abbreviations: BCVA, best corrected visual acuity; SD, standard deviation; IQR, inter-quartile range; VF-I4, Visual Function Index; IVI, Impact of Visual Impairment questionnaire; PSCC, posterior sub-capsular cataract.

than first eye surgery, while others have found no difference. $^{24,25}$ For early cataract, in particular, Amesbury et $\mathrm{al}^{13}$ retrospectively compared the change in visual function from before to after surgery between patients undergoing second eye surgery and patients who had bilateral surgery within the study period. They found a significant improvement of similar magnitude in both groups, implying second eye surgery is worthwhile even in patients with good BCVA. In a cross-sectional study, Tan et $\mathrm{al}^{14}$ compared the visual function of patients who had first eye surgery versus bilateral surgery, coming to a different conclusion: Tan et al suggested that second eye surgery was only beneficial when the fellow eye had BCVA of 6/12 or worse.

This paper builds upon such work by directly measuring the benefit after second eye surgery for early cataract and comparing this to the benefit observed in patients undergoing first eye surgery for early cataract. The improvement in visual function was similar between groups. The mean change in visual function in second eye patients exceeded clinical significance; whether or not second eye surgery truly improves visual function as much as first eye surgery, enough of a benefit may be expected to justify operating.

A secondary aim of this study was to investigate whether particular domains of the questionnaires were associated with greater improvement in overall visual function, to aid patient selection when assessing for cataract surgery. As suggested by previous work, ${ }^{20,21}$ reading small print and driving at night had the largest correlation with the overall change in visual function. While the majority of the selected questions demonstrated statistically significant correlations with outcome, the correlation coefficients were weak to moderate with wide confidence intervals. It seems that no single domain is reliably associated with the overall outcome.

Within the group of patients with BCVA of 6/9 or better, pre-operative BCVA is not a good indicator of the benefit of surgery. There was no significant correlation between the change in BCVA and the change in visual function from baseline to 4 months, and no difference in visual function outcome between patients with BCVA of $6 /$ 6 or better and patients with BCVA of $6 / 7.5$ or $6 / 9$. This study provides evidence to support the NICE guidance. ${ }^{7}$ BCVA cut-offs for cataract referrals restrict access to patients who may experience a clinically significant improvement in their visual symptoms, whether that cutoff is $6 / 12$ or even $6 / 7.5$.

It is expected that greater improvements in visual function will be observed in patients with PSCC, as these tend to affect visual function more than nuclear or cortical cataracts at an earlier stage. ${ }^{26,27}$ The mean change in visual function did indeed appear greater for patients with PSCC, although this was only statistically significant for the IVI. The difference in significance may be due to the different statistical tests used. Further work is required to confirm whether there is truly a larger benefit for patients with early PSCC.

The LOCS (iii) grade did not correlate significantly with the change in visual function. Previous work has correlated objective measures of cataract with preoperative self-reported visual function, reporting statistically significant correlations for some morphologies on the LOCS (iii) but not others. ${ }^{28,29}$ The results of this study suggest that grading the severity of cataract present is not 
Table 4 Correlation Between Change in Visual Function from Baseline to 4 Months and Age, Change in BCVA, and Response to Specific Questions at Baseline

\begin{tabular}{|c|c|c|}
\hline & \multicolumn{2}{|c|}{ Correlation with Overall Change in Visual Function Coefficient $(95 \% \mathrm{Cl}), p$ value } \\
\hline & VF-I4 & IVI \\
\hline Age & $-0.170(-0.449$ to 0.130$), 0.247^{\mathrm{a}}$ & $0.076(-0.216$ to 0.394$), 0.609^{\mathrm{a}}$ \\
\hline Change in BCVA & $-0.169(-0.485$ to 0.161$), 0.340^{b}$ & $-0.032(-0.346$ to 0.323$), 0.714^{\mathrm{a}}$ \\
\hline \multicolumn{3}{|c|}{ Response to specific question at baseline ${ }^{b}$} \\
\hline VF-I4 QI small print & 0.438 (0.154 to 0.678$), 0.002$ & $-0.384(-0.630$ to -0.066$), 0.007$ \\
\hline VF-14 Q5 navigating stairs & 0.385 (0.104 to 0.618$), 0.007$ & $-0.303(-0.544$ to -0.017$), 0.036$ \\
\hline VF-I4 QI4 night-time driving & 0.581 ( 0.288 to 0.774$),<0.001$ & $-0.589(-0.768$ to -0.345$),<0.001$ \\
\hline IVI QI2 small print & 0.236 (-0.056 to 0.505$), 0.111$ & $-0.494(-0.740$ to -0.203$),<0.001$ \\
\hline IVI QI6 trips/falls & $0.333(0.043$ to 0.587$), 0.021$ & $-0.508(-0.704$ to -0.233$),<0.00 \mathrm{I}$ \\
\hline IVI QI8 travelling & 0.288 (-0.003 to 0.546$), 0.047$ & $-0.520(-0.710$ to -0.253$),<0.001$ \\
\hline IVI QI9 navigating stairs & 0.262 (-0.065 to 0.555$), 0.072$ & $-0.544(-0.767$ to -0.269$),<0.001$ \\
\hline
\end{tabular}

Note: ${ }^{a}$ Spearman's $\rho$, 'Pearson's $r$.

Abbreviations: $\mathrm{Cl}$, confidence interval; BCVA, best corrected visual acuity in operated eye; VF-I4, Visual Function Index; ${ }^{16}$ IVI, Impact of Visual Impairment questionnaire. $^{17 .}$

useful in predicting the outcome of surgery when the BCVA is $6 / 9$ or better.

This study includes a sample relevant to current UK ophthalmological practice: early cataract cases where the decision to undergo surgery may not be clear-cut, and patients who do not meet referral criteria in health institutions where BCVA cut-offs are used. It is possible that the cultural background of patients could affect their response to questionnaires, so evidence from a UK sample is useful when assessing the benefit of surgery in the context of NICE guidance. Another strength is both short-term and long-term follow-up of visual function outcomes. The stability of the results over time mitigates as much as possible in studies of this nature the potential confounding influence of a placebo effect, which might be anticipated to wane with time.

On the other hand, there were practical limitations that affected the methodology of this study. As some patients completed the questionnaires on the day of surgery instead of at pre-operative assessment for logistical reasons, there is a possibility that BCVA and/or visual function might have deteriorated slightly between the time of listing and administration of the questionnaires. However, there was no significant difference in baseline questionnaire scores (VF-14 independent samples $t$-test $\mathrm{p}=0.662$; IVI MannWhitney $U$-test $\mathrm{p}=0.425$ ) nor in change in questionnaire scores from baseline to 4 months (VF-14 $\mathrm{p}=0.398$; IVI $\mathrm{p}=0.748$ ) between patients recruited on the day of surgery and patients recruited from pre-operative assessment.

The results comparing first eye surgery to second eye surgery may have been affected by some patients in the first eye group undergoing second eye surgery within the time frame of the study. Ten (45\%) patients had second eye surgery within the 12-month follow-up period and 7 of these $(32 \%)$ were within 4 months. This could overestimate the benefit of first eye surgery. The statistical tests comparing first eye and second eye patients used 4-month data only to reduce the effect of further surgery on these results. Based on previous work, first eye surgery was expected to provide a larger benefit than second eye surgery, ${ }^{25}$ so the p-value reported here is conservative; no significant difference was found despite the possible bias towards greater improvement in first eye patients.

There was no control group in this study, so the placebo effect cannot be ruled out as a cause of the improvements in visual function observed. Patient expectations can affect satisfaction and questionnaire outcomes after surgery; ${ }^{30,31}$ although the direction of correlation varies between studies, the findings of some authors that positive expectations correlate with better outcomes might hint at a placebo effect in some surgical procedures. A 2014 review of randomized placebo-controlled surgery trials 
found that half of the reviewed studies showed no benefit over placebo for the investigated intervention, and argued that such studies can be ethically justified due to the reduced risk in the placebo arm. ${ }^{32}$ However, cataract surgical risk is low in comparison with most procedures, and ethical concerns and recruitment difficulties may explain why studies without placebo controls are the standard approach for cataract surgery outcomes.

A more easily justified control group for cataract studies may be patients diagnosed with cataract who elect not to undergo surgery. This approach would control for regression to the mean, if not for placebo effects. However, the self-selecting rather than randomized nature of such a control group would not control for confounding variables and would likely have introduced a bias into the results.

\section{Conclusions}

This study fills the gap in the evidence supporting the NICE guidance, by demonstrating that patients with early cataract - as defined by pre-operative BCVA of $6 / 9$ or better in the worst eye - show a significant increase in visual function after surgery. Visual function improved by the same degree after either first or second eye surgery. Neither age nor change in BCVA correlated with the change in visual function. Patients with PSCC may benefit more from early surgery than patients with other types of cataract, but further work is required to confirm this.

The improvement in visual function observed is clinically significant and remained unchanged one year after surgery, demonstrating that there is no clinical justification to restrict referrals based on BCVA cut-offs for either first or second eye surgery. ${ }^{7}$ Assessing patient reported visual function may give a more realistic indication of the benefit of early cataract surgery than relying solely on pre-operative BCVA.

\section{Abbreviations}

BCVA, best corrected visual acuity; NICE, National Institute for Health and Clinical Excellence; UK, United Kingdom; LOCS (iii), Lens Opacity Classification System; VF-14, Visual Function Index; IVI, Impact of Visual Impairment; PSCC, posterior sub-capsular cataract.

\section{Data Sharing Statement}

De-identified participant data are available upon reasonable request from the corresponding author, umiya.harley@nhs.net.

\section{Acknowledgments}

The authors wish to thank Dr Patrick Kearns and the Golden Jubilee National Hospital staff for allowing access and accommodating study activity. Eilidh Farquhar and Umiya Harley are co-first authors of this study.

\section{Author Contributions}

All authors made significant contributions to the work reported, whether in the conception, study design, execution, acquisition of data, and/or analysis and interpretation. All authors drafted and/or critically reviewed and/or substantially revised the article. All authors agreed with the decision to submit to Clinical Ophthalmology, reviewed and agreed upon all versions of the article for submission and publication, and agreed to be accountable for the contents of this article.

\section{Funding}

Funding was received from the Royal Blind Ophthalmology Major Research Grant 2015, awarded by The Royal College of Surgeons, Edinburgh.

\section{Disclosure}

The authors report no conflicts of interest.

\section{References}

1. Kessel L, Andresen J, Erngaard D, Flesner P, Tendal B, Hjortdal J. Indication for cataract surgery. Do we have evidence of who will benefit from surgery? A systematic review and meta-analysis. Acta Ophthalmol. 2016;94(1):10-20. doi:10.1111/aos.12758

2. Saw SM, Tseng P, Chan WK, Chan TK, Ong SG, Tan D. Visual function and outcomes after cataract surgery in a Singapore population. $J$ Cataract Refract Surg. 2002;28(3):445-453. doi:10.1016/S0886-3350(01)01016-1

3. Charalampidou S, Loughman J, Nolan J, et al. Prognostic indicators and outcome measures for surgical removal of symptomatic nonadvanced cataract. Arch Ophthalmol. 2011;129(9):1155. doi:10.1001/ archophthalmol.2011.111

4. Fung SSM, Luis J, Hussain B, Bunce C, Hingorani M, Hancox J. Patient-reported outcome measuring tools in cataract surgery: clinical comparison at a tertiary hospital. J Cataract Refract Surg. 2016;42 (12):1759-1767. doi:10.1016/j.jcrs.2016.08.037

5. Gray CS, Karimova G, Hildreth AJ, Crabtree L, Allen D, O'Connell JE. Recovery of visual and functional disability following cataract surgery in older people: Sunderland Cataract Study. $J$ Cataract Refract Surg. 2006;32(1):60-66. doi:10.1016/j. jcrs.2005.07.040

6. Lum F, Schein O, Schachat AP, Abbott RL, Hoskins HD, Steinberg EP. Initial two years of experience with the AAO National Eyecare Outcomes Network (NEON) cataract surgery database. Ophthalmology. 2000;107(4):691-697. doi:10.1016/S0161-6420(99) 00184-0

7. National Institute for Health and Care Excellence. Cataracts in Adults: management. NICE; 2017. Available from: www.nice.org.uk/gui dance/ng77. Accessed December 1, 2021. 
8. Royal College of Ophthalmologists. RCOphth follow up survey finds continued cataract rationing imposed by CCGs despite NICE Guidance; 2019. Available from: https://www.rcophth.ac.uk/2019/ 04/rcophth-follow-up-survey-finds-continued-cataract-rationingimposed-by-ccgs-despite-nice-guidance/. Accessed March 20, 2020.

9. Northamptonshire Local Optical Committee. NHS Nene \& NHS Corby CCG cataract referral form; 2017. Available from: http://north antsloc.org/pages/DownloadList.html. Accessed March 20, 2020.

10. Essex Local Optical Committee. Mid Essex cataract restriction policy; 2016. Available from: http://essex-loc.org/mid-south-essex. Accessed March 20, 2020.

11. Bellan L. Why are patients with no visual symptoms on cataract waiting lists? Can J Ophthalmol. 2005;40(4):433-438. doi:10.1016/ S0008-4182(05)80002-X

12. Garcia-Gutierrez S, Quintana JM, Aguire U, et al. Impact of clinical and patient-reported outcomes on patient satisfaction with cataract extraction. Heal Expect. 2014;17(6):765-775. doi:10.1111/j.13697625.2012.00801.x

13. Amesbury EC, Grossberg AL, Hong DM, Miller KM. Functional visual outcomes of cataract surgery in patients with 20/20 or better preoperative visual acuity. $J$ Cataract Refract Surg. 2009;35 (9):1505-1508. doi:10.1016/j.jcrs.2009.04.031

14. Tan ACS, Tay WT, Zheng YF, et al. The impact of bilateral or unilateral cataract surgery on visual functioning: when does second eye cataract surgery benefit patients? $\mathrm{Br} J$ Ophthalmol. 2012;96 (6):846-851. doi:10.1136/bjophthalmol-2011-301233

15. Chylack LT. The lens opacities classification system III. Arch Ophthalmol. 1993;111(6):831-836. doi:10.1001/archopht.1993.010900 60119035

16. Steinberg EP. The VF-14: an index of functional impairment in patients with cataract. Arch Ophthalmol. 1994;112(5):630. doi:10.1001/archopht.1994.01090170074026

17. Weih LM, Hassell JB, Keeffe J. Assessment of the impact of vision impairment. Invest Ophthalmol Vis Sci. 2002;43(4):927-935.

18. Finger RP, Fenwick E, Marella M, et al. The relative impact of vision impairment and cardiovascular disease on quality of life: the example of pseudoxanthoma elasticum. Health Qual Life Outcomes. 2011;9 (1):113. doi:10.1186/1477-7525-9-113

19. Black N, Browne J, Van Der Meulen J, Jamieson L, Copley L, Lewsey J. Is there overutilisation of cataract surgery in England? Br J Ophthalmol. 2009;93(1):13-17. doi:10.1136/bjo.2007.136150

20. Grzybowski A, Kanclerz P, Muzyka-Woźniak M. Methods for evaluating quality of life and vision in patients undergoing lens refractive surgery. Graefes Arch Clin Exp Ophthalmol. 2019;257 (6):1091-1099. doi:10.1007/s00417-019-04270-w
21. Colin J, El Kebir S, Eydoux E, Hoang-Xuan T, Rozot P, Weiser M. Assessment of patient satisfaction with outcomes of and ophthalmic care for cataract surgery. J Cataract Refract Surg. 2010;36 (8):1373-1379. doi:10.1016/j.jcrs.2010.02.015

22. Bilbao A, Quintana JM, Escobar A, et al. Responsiveness and clinically important differences for the VF-14 Index, SF-36, and visual acuity in patients undergoing cataract surgery. Ophthalmology. 2009;116(3):418-424.e1. doi:10.1016/j.ophtha.2008.11.020

23. Quintana JM, Aguirre U, Las-Hayas C, Gonzalez N, Garcia S, Escobar A. Use of the patient acceptable symptom state and the minimal clinically important difference to evaluate the outcomes of cataract extraction. Am J Ophthalmol. 2011;152(2):234-243.e3. doi:10.1016/j.ajo.2011.01.045

24. Frampton G, Harris P, Cooper K, Lotery A, Shepherd J. The clinical effectiveness and cost-effectiveness of second-eye cataract surgery: a systematic review and economic evaluation. Health Technol Assess. 2014;18(68):1-206. doi:10.3310/hta18680

25. Ishikawa T, Desapriya E, Puri M, Kerr JM, Hewapathirane DS, Pike I. Evaluating the benefits of second-eye cataract surgery among the elderly. $J$ Cataract Refract Surg. 2013;39 (10):1593-1603. doi:10.1016/j.jcrs.2013.08.033

26. Pesudovs K, Coster DJ. Cataract surgery reduces subjective visual disability. Aust $N Z$ J Ophthalmol. 1997;25(SUPPL. 1):5-7. doi:10.1111/j.1442-9071.1997.tb01742.x

27. Stifter E, Sacu S, Weghaupt H. Functional vision with cataracts of different morphologies: comparative study. J Cataract Refract Surg. 2004;30(9):1883-1891. doi:10.1016/j.jcrs.2004.01.038

28. Skiadaresi E, McAlinden C, Pesudovs K, Polizzi S, Khadka J, Ravalico G. Subjective quality of vision before and after cataract surgery. Arch Ophthalmol. 2012;130(11):1377. doi:10.1001/ archophthalmol.2012.1603

29. Pan A-P, Wang Q-M, Huang F, Huang J-H, Bao F-J, Yu A-Y. Correlation among lens opacities classification system III grading, visual function index-14, pentacam nucleus staging, and objective scatter index for cataract assessment. Am J Ophthalmol. 2015;159 (2):241-247.e2. doi:10.1016/j.ajo.2014.10.025

30. Waljee J, McGlinn EP, Sears ED, Chung KC. Patient expectations and patient-reported outcomes in surgery: a systematic review. Surgery. 2014;155(5):799-808. doi:10.1016/j.surg.2013.12.015

31. Pager CK. Expectations and outcomes in cataract surgery. Arch Ophthalmol. 2004;122(12):1788. doi:10.1001/archopht.122.12.1788

32. Wartolowska K, Judge A, Hopewell S, et al. Use of placebo controls in the evaluation of surgery: systematic review. BMJ. 2014;348(212): g3253. doi:10.1136/bmj.g3253
Clinical Ophthalmology

\section{Publish your work in this journal}

Clinical Ophthalmology is an international, peer-reviewed journal covering all subspecialties within ophthalmology. Key topics include: Optometry; Visual science; Pharmacology and drug therapy in eye diseases; Basic Sciences; Primary and Secondary eye care; Patient Safety and Quality of Care Improvements. This journal is indexed on PubMed

\section{Dovepress}

Central and CAS, and is the official journal of The Society of Clinical Ophthalmology (SCO). The manuscript management system is completely online and includes a very quick and fair peer-review system, which is all easy to use. Visit http://www.dovepress.com/ testimonials.php to read real quotes from published authors. 